\title{
Generation of Electricity by Using Footsteps as a Source of Energy
}

\author{
P. R. Magdum, S. J. Chikhale, A. S. Rajole, S. S. Jedhe \\ (Department of Mechanical Engineering, M. E. S. College of Engineering, S.P. Pune University, India)
}

\begin{abstract}
Electricity is a basic part of nature and it is one of the most widely used forms of energy across the globe. We get electricity, (which is a secondary energy source) from the conversion of other sources of energy, like coal, natural gas, oil, nuclear power and other natural sources, which are called primary sources. Researches show that the world has already had its enough shares of its energy resources. Fossil fuels pollute the environment. Nuclear energy requires careful handling of both raw as well as waste material. Researches shows that large amount of power is generated from non-renewable energy resources compared to that of renewable energy resources. The extensive usages of available resources in recent years created a demand for the future generation. To overcome this problem we need to utilize renewable energy sources for power generation and conservation. Therefore the focus now is shifting more and more towards the renewable source of energy, which are essential and non-polluting. The goal of this paper is to show the detailed survey of how jumping platform can be now used as a source of power.
\end{abstract}

Keywords: Renewable energy, rack and pinion, kinetic energy, electro-mechanical unit,, roller mechanism, chain sprocket.

\section{Introduction}

Is anyone happy with the current situation of electricity in India? So, this is our small step to try to improve this situation by our project. First of all what does electricity mean to us??? Electricity- secondary source of energy i.e. converted from other sources. We need it for every small thing, still notice its importance only during load shedding. Man has needed the use energy at an increasing rate for his sustenance and wellbeing ever since he came on the earth a few million years ago. Primitive man required energy primarily in the form of wood. He derived this by eating plants or animals, which he hunted. Subsequently he discovered force and his energy needs increased as he started to make use of wood and other bio-mass to supply the energy needs for cooking as well as for a keeping himself warm. With the passage of time, man started to cultivate land for agriculture. He added a new dimension to the use of energy by domesticating and training animals to work for him. For this project the conversion of force energy is converted into electrical energy. In this project we have tried to generate electricity through the human powered mechanical energy.

\subsection{Problem Statement}

Energy is utilized by each and every organism in the universe for its survival. As in this fast moving world, the population is increasing day by day and the conventional energy sources are lessening. The extensive usage of energy has resulted in an energy crisis over the few years. Also, electricity production has become one of important causes of global warming. This is due to the immense heat being dissipated during the process. This heat contributes to the gradual increase in Earth temperature. Furthermore, burning of fossil fuels also produces an end product of carbon dioxide and sometimes carbon monoxide which are harmful to human health. Carbon dioxide tends to radiate heat back into Earth. In addition, the usage of fossil fuel for generation of electricity is very costly. A large sum could be saved by using a renewable energy. This would enable invest in future projects rather than just spending it on purchasing fossil fuels alone.Therefore to overcome this problem we need to implement the techniques of optimal utilization of conventional sources for conservation of energy. The conventional sources of energy are generally non-renewable sources of energy, which are being used since a long time. Energy generated by using wind, tides, solar, geothermal heat, and biomass including farm and animal waste is known as nonconventional energy. All these sources are natural, renewable or inexhaustible and do not cause environmental pollution and are eco-friendly. Moreover they do not require heavy expenditure. To improve the power generation technologies and to make them more sustainable, non -conventional technologies have been discovered. The non-conventional sources of energy are abundant in nature. Most of the non conventional sources have been boons at hand only to the well developed countries. The developing countries that lag behind in technical assets and financial limitations are striving to install the technologies of the latest trends and advanced versions. With the vast development of the technologies and understanding them, many 
other creative techniques of power generation have been emerged. The newly developed techniques are aimed at cost effectiveness. Thus, they become more affordable to the countries like India, where installation cost and space occupancy are serious issues. One such creative technique is power generation through human powered mechanical energy. The idea is to tap the energy that a human would release while he is jumping. It is achieved by using rack and pinion mechanism. Rack and pinion mechanism, on the contrary, is clean and environmentally friendly, although, the components of the device require regular oiling and maintenance. The initial investment can be recovered within a relatively short time. Jumping is the one of the most common activity in day to day life. One can maintain good health only if he does daily and regular exercise. It is one of the best exercises to maintain body fitness. When a person jumps, he loses energy to the ground surface in the form of impact, vibration, sound etc., due to the transfer of his weight on to the ground surface, through feet falls on the ground during every leap. This energy can be tapped and converted into usable electrical form.In this project, we have used a similar concept to derive electricity using the "jump" energy. The working principle is simple. When a person jumps on the spring cladded platform of the device, the platform will dip down due to the weight of the person. The downward movement of the platform is connected to a specific rack and pinion mechanism, which results in the rotation of the shaft of an electrical generator, to produce electrical energy. The platform reverts back to its original position due to negating springs provided in the device. If such a device is embedded on gymnasium floors or places of human attraction e.g. city malls, amusement parks, etc. the electricity generated by these devices can be used for various day to day applications.

\section{Concept}

While jumping, the person possess some energy and it is being wasted. This energy can be utilized to produce power by using a special arrangement. It is an Electro-Mechanical unit. It utilizes both mechanical technologies and electrical techniques for the power generation and its storage. Whenever the person is allowed to jump on the base (plywood) it gets pressed downwards then the springs are attached at each corner of the plywood is compressed and the rack which is attached to the plywood moves linearly downward. Since the rack has teeth connected to gears, there exists conversion of linear motion of rack into rotary motion of gears but the two gears rotate in opposite direction. A flywheel is mounted on the shaft whose function is to regulate the fluctuation in the energy and to make the energy uniform. So that the shafts will rotate with certain R.P.M. these shafts are connected through intermediate gears and sprockets to the dynamo, which converts the mechanical energy into electrical energy. The conversion will be proportional to the load being applied. The springs being attached will regain its original length and also cause the plywood to return back to its initial position. This results in the upward motion of the rack which is attached to the plywood thereby rotating the gears. Thus both the downward and upward linear motion of the rack is utilized to generate electricity. Whenever an armature rotates between the magnetic fields of south and north poles, an E.M.F is induced in it. So, for inducing the E.M.F.armature coil has to rotate, for rotating this armature it is connected to a long shaft. By rotating same e.m.f is induced, for this rotation energy of person jumping on the plywood is utilized. This generated power can be amplified and stored by using different electrical devices.

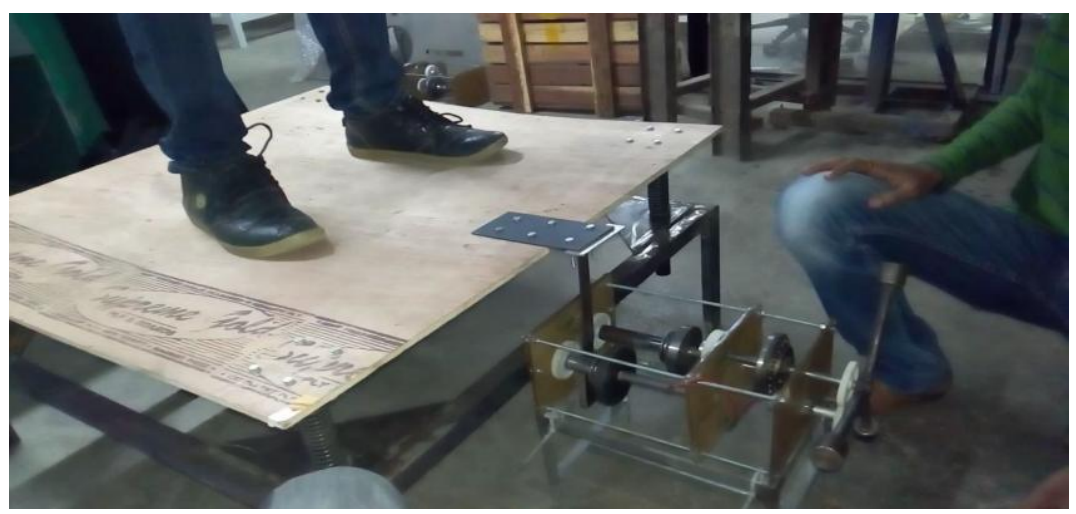

Fig.1. Concept model

\section{Constructional Details}

The system comprises of a base (plywood) which rests on a strong platform with four springs in between them. The spring system consists of four springs with a pipe provided to each one to serve as a guide for the springs. The pipe is attached to the rectangular plate which is attached to the plywood. To guide the pipe triangular plates with suitable hole is attached at each corner to the platform as shown in Fig.2. The gearbox consists of a both side toothed rack, two pinions, four intermediate gears, three sprockets and an output gear. 
The rack moves linearly between two pinions. The two pinions are connected to two separate sprockets which are constrained to rotate in one direction only (say anti-clockwise). The sprocket is thereby connected to two intermediate gears. When the rack moves linearly downward during the impact of load on the platform, it causes both the pinion to rotate. But the direction of motion is opposite, that is one of the pinions rotates clockwise while the other anti-clockwise. These pinions provide motion to the sprocket but as sprockets are constrained to move in anticlockwise direction, only one of the sprocket rotates during the downward motion of the rack. This rotating rack causes intermediate gear coupled to it to rotate and thereby transfer the motion to another sprocket. This sprocket rotates the gear attached to the flywheel and this gear in turn rotates the output gear. The motion available at the output gear is utilized to run the dynamo to generate electricity.Now, the compressed spring during the downward motion of the base expands to obtain its original length causing the base (plywood) to rise back. During this motion the rack moves upwards and rotates both the pinions in opposite direction. These pinions causes the sprocket to rotate. But only one sprocket will rotate and this time the other one. Thus, both the motion of the rack is utilized that is upward and downward.

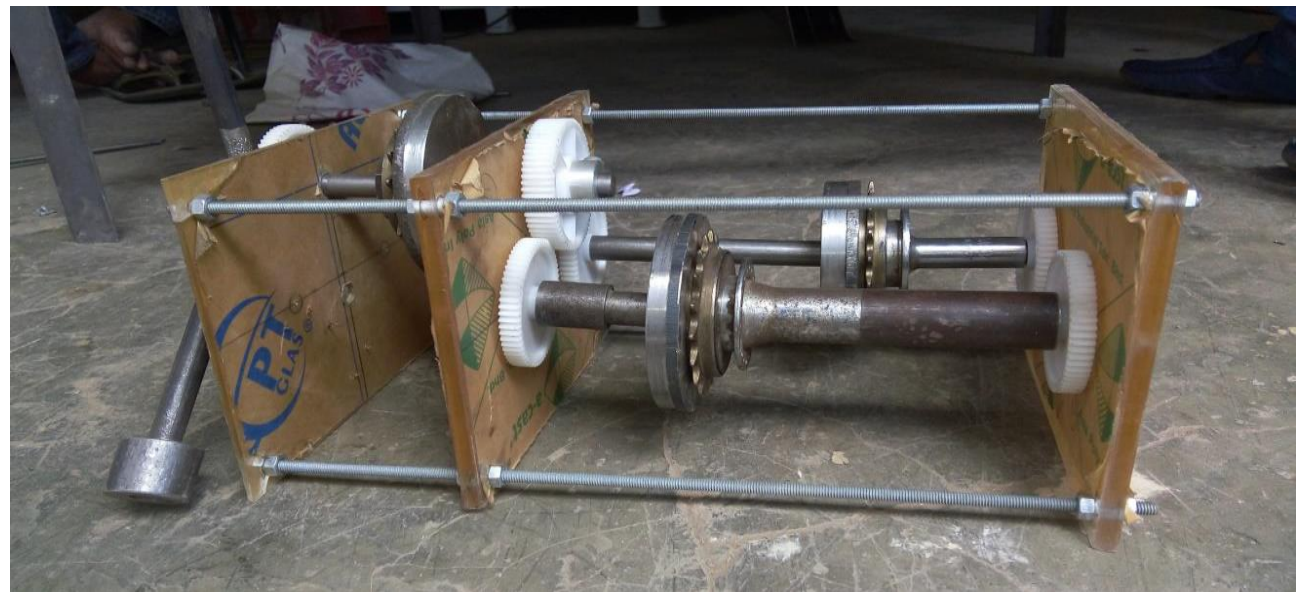

Fig.3. Assembly of gearbox

\section{Experimental Investigation}

When a person jumps on the base (plywood) his weight causes an impact on it. This load is distributed uniformly over the plywood. This load causes the springs to compress. The rack which is attached to the base moves linearly downward and rotates the two pinions meshing with it.It is obvious that the pinions will rotate in opposite direction. These pinions while rotating causes the sprocket to rotate. As sprockets are constrained to rotate in one direction, only one of the sprockets will be in motion during a particular rack movement i.e. downward or upward. When the rack moves linearly downward during the impact of load on the platform, it causes both the pinion to rotate. But the direction of motion is opposite, that is one of the pinions rotates clockwise while the other anti-clockwise. These pinions provide motion to the sprocket but as sprockets are constrained to move in anticlockwise direction, only one of the sprocket rotates during the downward motion of the rack. This rotating rack causes intermediate gear coupled to it to rotate and thereby transfer the motion to another sprocket. This sprocket rotates the gear attached to the flywheel and this gear in turn rotates the output gear. The motion available at the output gear is utilized to run the dynamo to generate electricity. Now, the compressed spring during the downward motion of the base expands to obtain its original length causing the base (plywood) to rise back. During this motion the rack moves upwards and rotates both the pinions in opposite direction. These pinions causes the sprocket to rotate. But only one sprocket will rotate and this time the other one. This motion is then transferred to the output gear through the intermediate gears and the sprocket. Thus, both the motion of the rack is utilized that is upward and downward. The motion at the output gear causes the dynamo to generate electricity. 


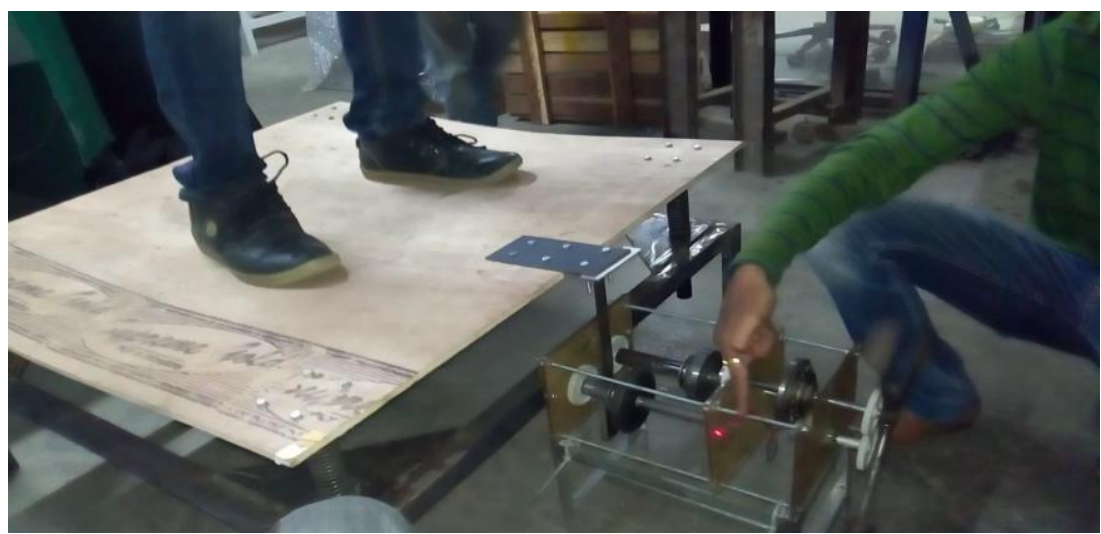

Fig.4 Generation of electricity during downward motion of rack

A flywheel is also provided to compensate for the reduction in motion. The primary function of flywheel is to act as an energy accumulator. It reduces the fluctuations in speed. It absorbs the energy when demand is less and releases the same when it is required.

Table1 Power developed at various loads

\begin{tabular}{|l|l|l|}
\hline $\begin{array}{l}\text { Sr. } \\
\text { No. }\end{array}$ & $\begin{array}{l}\text { Load } \\
(\mathbf{k g})\end{array}$ & $\begin{array}{l}\text { Power } \\
(\mathbf{W})\end{array}$ \\
\hline 1 & 50 & 0.82 \\
\hline 2 & 55 & 0.9 \\
\hline 3 & 60 & 0.98 \\
\hline 4 & 65 & 1.06 \\
\hline 5 & 70 & 1.14 \\
\hline 6 & 80 & 1.31 \\
\hline
\end{tabular}

Table2 Results

\begin{tabular}{|l|l|l|l|l|l|}
\hline $\begin{array}{l}\text { Sr. } \\
\text { No. }\end{array}$ & $\begin{array}{l}\text { Mass } \\
(\mathrm{kg})\end{array}$ & Voltage $(\mathrm{V})$ & $\begin{array}{l}\text { Resistance } \\
(\Omega)\end{array}$ & $\begin{array}{l}\text { Current } \\
(\mathrm{A})\end{array}$ & $\begin{array}{l}\text { Power(watt } \\
)\end{array}$ \\
\hline 1 & 50 & 2.5 & 50 & 0.05 & 0.125 \\
\hline 2 & 55 & 2.94 & 50 & 0.0588 & 0.173 \\
\hline 3 & 60 & 3.5 & 50 & 0.07 & 0.245 \\
\hline 4 & 65 & 4 & 50 & 0.08 & 0.32 \\
\hline 5 & 70 & 4.3 & 50 & 0.086 & 0.3698 \\
\hline 6 & 80 & 5.2 & 50 & 0.104 & 0.5408 \\
\hline
\end{tabular}

\section{Efficiency}

Since, the power is obtained by jumping on the base it can be considered as an input and the power obtained from the dynamo is output. These two quantities are sufficient to calculate the efficiency of the model (setup).

Average theoretical power $=(0.82+0.9+0.98+1.06+1.14+1.31) / 6=1.035 \mathrm{~W}$

Average actual power $=(0.125+0.173+0.245+0.32+0.3698+0.5408) / 6=0.2956 \mathrm{~W}$

Efficiency $=$ Output $/$ Input $=0.2856$ or $28.56 \%$

\subsection{Graphs}

Graphs of power vs. load, current vs. load and voltage vs. load are plotted below

- It can be seen from the above plotted graph 5 that as load increases power increases.

- The curve is linear.

- It is observed from the above plotted graph 6 that as load increases power increases.

- It is observed from the above plotted graph 7 that as load increases current increases. 


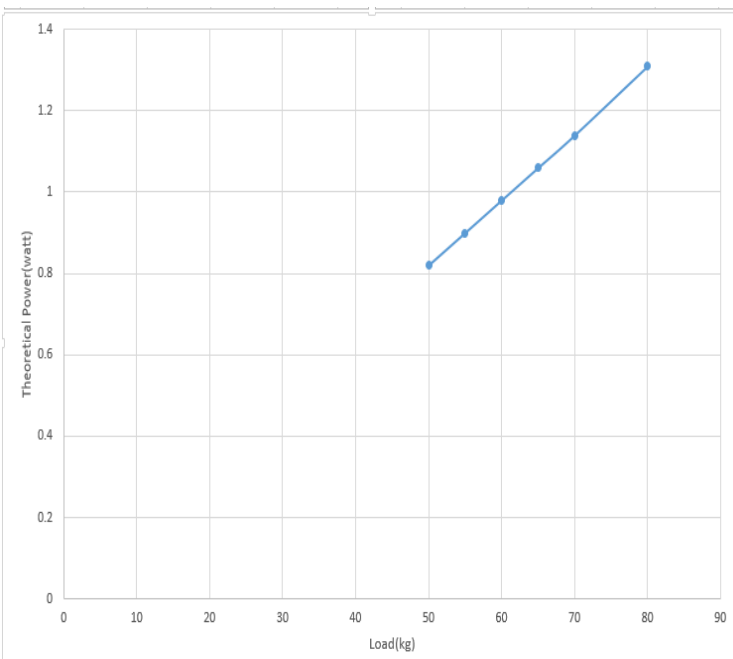

Graph 5. Graph of power vs load

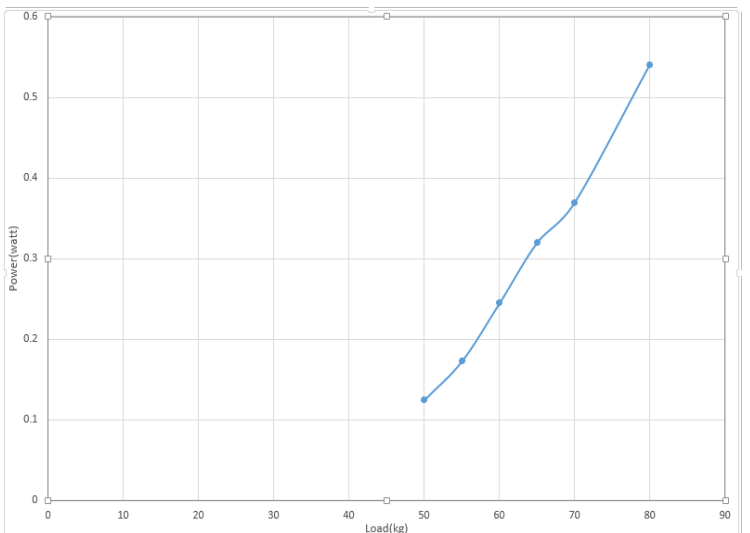

Graph 6. Graph of Power vs Load

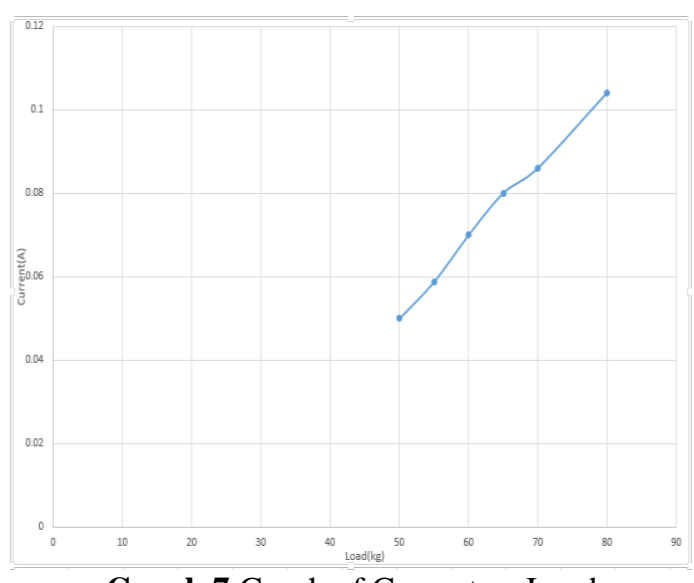

Graph 7 Graph of Current vs Load

- It is observed from the above plotted graph 7 that as load increases voltage increases.

It can be observed from the above graph 8 that

- both theoretical and actual power increases with increase in load

- actual power is lower than the theoretical power. 


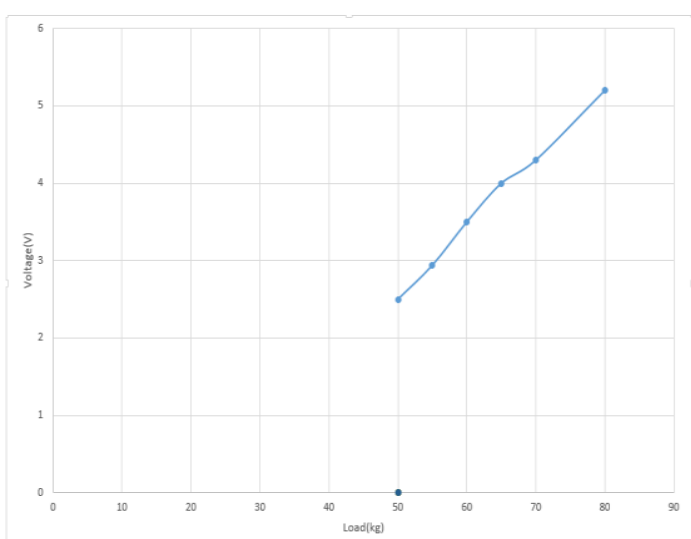

Graph 8 Graph of Voltage vs Load

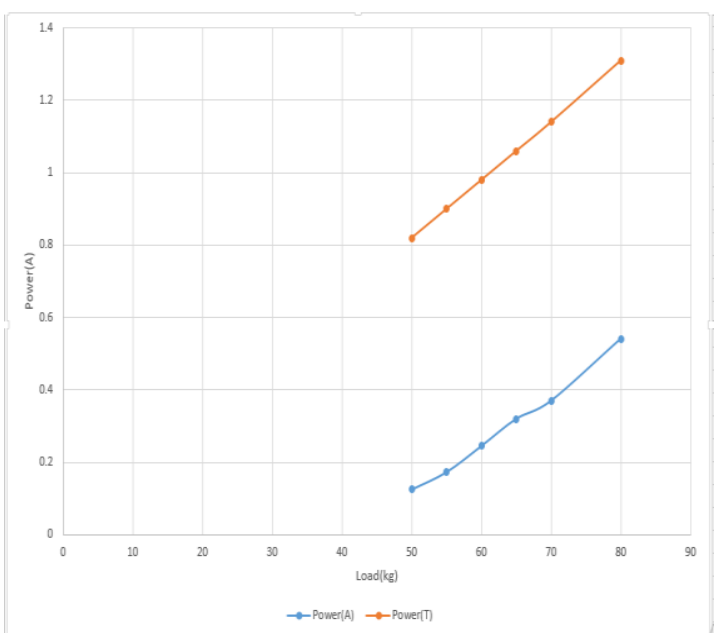

Graph 9. Graph of Power (theoretical and actual) vs Load

1. It is concluded that

\section{Conclusion}

- as load increases on the base (plywood) voltage increases

- as load increases on the base (plywood) current increases

- as load increases on the base (plywood) power increases

- the efficiency of the setup is found to be $28.56 \%$.

2 . The average actual power obtained is $0.2956 \mathrm{~W}$.

Therefore, power developed per minute $=0.2956 \times 60=17.74 \mathrm{~W}$

3. If a person jumps for 10 minutes on the base of the setup,

Power developed in 10 minutes $=177.4 \mathrm{~W}$

\section{References}

[1] M.Sailaja , M. Raja Roy, S. Phani Kumar, “ Design of Rack and Pinion Mechanism for Power Generation at Speed Breakers"

[2] Mukti Nath Gupta, Suman and S.K. Yadav, "Electricity generation due to vibration of moving vehicles using piezoelectric effect", Advance in Electronic and Electric Engineering, Vol. 4 No. 3, pp. 313-318, 2014. ISSN 22311297.

[3] Parthiba Arun and Divyesh Mehta, "Eco-friendly electricity generator using scintillating piezo", International Journal of Engineering Research and Applications, Vol. 3 No.5, pp. 478-482, 2013.

[4] Henry A. Sodano and Daniel J. Inman, "Estimation of electric charge output for piezoelectric energy harvesting", Strain Journal, Vol. 40 No. 2, pp. 49- 58, 2004.

[5] Kiran Boby, Aleena Paul K, Anumol C and Nimisha, "Foot step power generation using piezoelectric transducer", International Journal of Engineering and Innovative Technology (IJEIT), Vol.3No. 1, Issue 10, 2014.

[6] Amod kumar pandey, Somya Yadav and Tanu Srivastava, "Electrifying roller-coaster ride through speed breakers", International journal of computer applications, Vol. 67 No.21, 2013. 
[7] A.Padma Rao, A.Kiran Kumar and S.Suresh, "Power Generation from Speed Breaker by Rack and Ratchet Mechanism", International Journal of Current Engineering and Technology, Vol. 1 No. 2, 2014. E-ISSN 2277 4106, P-ISSN 2347-5161.

[8] Aniket Mishra, Pratik Kale and Atul Kamble, "Electricity generation from speed breakers", The International Journal of Engineering and Science (IJES), Vol.2 No. 11, pp. 25-27, 2013.ISSN (e) 2319-1813 ISSN (p) 2319-1805.

[9] Pankaj D.Jagtap, Sanket D.Pardeshi, Angad G.Khade and Varun Sathe, "A Review: Comparison of different mechanism for electricity generation using speed breaker", Multidisciplinary journal of research in engineering and technology, Vol. 1 No. 2, pp. 202-206, 2014. ISSN 2348-6953.

[10] Qihui Yu - Maolin Cai - Yan Shi - Zichuan Fan, "optimization of the energy efficiency of a piston compressed air engine", Journal of Mechanical Engineering, Vol. 60 No.6, pp. 395-406, 2014.

[11] Chih-Yung Huang, Cheng-Kang $\mathrm{Hu}$, Chih-Jie Yu and Cheng-Kuo Sung, "Experimental investigation on the performance of a compressed air driven piston engine", International Journal of Energies, Vol. 6, pp. 1731-1745, 2013.

[12] K.Ravivarma, B.Divya, C.P.Prajith, A.Sivamurugan and K.Vengatesan, "Power generation using hydraulic mechanism at speed bumper", International Journal of Scientific and Engineering Research, vol. 4 No. 6, 2013. ISSN 2229-5518.

[13] R.Mikalsen, A.P.Roskilly, "The design and simulation of a two-stroke free-piston compression ignition engine for electrical power generation”, Applied Thermal Engineering, Vol. 28 No.1, pp. 589-600, 2008.

[14] Rajesh Kannan Megalingam, Pranav Sreedharan Veliyara, Raghavendra Murali Prabu and Rocky Katoch, "Pedal Power Generation", International Journal of Applied Engineering Research, Vol. 7No. 11, 2012. ISSN 0973-4562.

[15] Antonin Stribrsky, Katerina Hyniova, Jaroslav Honcu and Ales Kruczek, "Energy Recuperation in Automotive Active Suspension with Linear Electric Motor", Proceedings of the 15th Mediterranean Conference on Control\& Automation,July 27-29, 2007, Athens - Greece.

[16] B. Santhosh Sarma, V. Jyothi, D. Sudhir, "Design of Power Generation Unit Using Roller Mechanism", IOSR Journal of electrical and electronics Engineering (IOSR-JEEE) Vol. 9 No. 3, pp 55-60, 2014. ISSN: 2278-1676.

[17] Junzhi Zhan, Xin Lu, Junliang Xue, and Bos Li, "Regenerative Breaking System for Series Hybrid Electric City Bus",The world Electric Vehicle Journal, Vol. 2 No. 4, pp 0363. ISSN 2032-6653.

[18] Vimalkumar A. Patel "Energy Harvesting by Utilizing Weight of Vehicle at Highway Toll Plaza"

[19] Md. Saiful Islam et al:"Generation of Electricity Using Road Transport Pressure".

[20] Ch. Bhanu Prakash et al: "Road Power Generation by Speed Breaker"

[21] Tom Jose V et al "Electricity Generation from Footsteps; A Regenerative Energy Resource"

[22] Rajat Gupta et al."A Revolutionary Technique of Power Generation through Speed Breaker Power Generators" 